Boise State University

ScholarWorks

$5-24-2006$

\title{
Investigating the Stratigraphy of an Alluvial Aquifer Using Crosswell Seismic Traveltime Tomography
}

Geoff J.M. Moret

Pennsylvania State University

Michael D. Knoll

Boise State University

Warren Barrash

Boise State University

William P. Clement

Boise State University 


\title{
Investigating the stratigraphy of an alluvial aquifer using crosswell seismic traveltime tomography
}

\author{
Geoff J. M. Moret ${ }^{1}$, Michael D. Knoll ${ }^{2}$, Warren Barrash ${ }^{2}$, and William P. Clement ${ }^{2}$
}

\begin{abstract}
In this study, we investigate the use of crosswell P-wave seismic tomography to obtain spatially extensive information about subsurface sedimentary architecture and heterogeneity in alluvial aquifers. Our field site was a research wellfield in an unconfined aquifer near Boise, Idaho. The aquifer consists of $\mathrm{a} \sim 20$-m-thick sequence of alluvial cobble-and-sand deposits, which have been subdivided into five stratigraphic units based on neutron porosity logs, grainsize analysis, and radar reflection data. We collected crosswell and borehole-to-surface seismic data in wells $17.1 \mathrm{~m}$ apart. We carefully considered the impact of well deviation, data quality control, and the choice of inversion parameters. Our linearized inverse routine had a curved-ray forward model and used different grids for forward modeling and inversion. An analysis of the model covariance and resolution matrices showed that the velocity models had an uncertainty of $<10 \mathrm{~m} / \mathrm{s}$, a vertical resolution of $\sim 1 \mathrm{~m}$, and a horizontal resolution of $\sim 5 \mathrm{~m}$. The velocity in the saturated zone varied between $2100 \mathrm{~m} / \mathrm{s}$ and $2700 \mathrm{~m} / \mathrm{s}$. Inclusion of the borehole-to-surface data eliminated the $\mathrm{X}$ shaped pattern that is a common artifact in crosswell tomography, and the increased angular coverage also improved the accuracy of the model near the top of the tomogram. The final velocity model is consistent with previous stratigraphic analyses of the site, although the locations of some of the unit boundaries differ by as much as $2 \mathrm{~m}$ in places. The results of this study demonstrate that seismic tomography can be used to image the sedimentary architecture of unconsolidated alluvial aquifers, even when the lithologic contrasts between units are subtle.
\end{abstract}

\section{INTRODUCTION}

Subsurface sedimentary architecture can have a significant influence on the movement of groundwater. For coarse-braided stream deposits, computer modeling of contaminant transport has shown that coherent sedimentary structures are important to the outcome (Jussel et al., 1994b). Since many aquifers in this type of sedimentary environment are contaminated (e.g., Barrash et al., 1997; Regli et al., 2002), there is considerable interest in using geophysics to characterize their subsurface structure in order to improve models of groundwater flow and contaminant transport.

One method that can be used to image the subsurface is seismic traveltime tomography. Seismic traveltime tomography involves recording the traveltimes between many source and receiver positions, and then inverting these data to produce a velocity model consistent with these observations. These velocity images can be used to define aquifer geometry at a scale useful for hydrologic modeling (e.g., Hubbard et al., 2001; Daley et al., 2004). Some studies (e.g., Hyndman et al., 2000; Ellefsen et al., 2002) have used seismic tomograms to infer field-scale petrophysical relationships between seismic properties and hydraulic properties. Seismic tomography (both crosswell and surface refraction) can be used in situations where surface seismic reflection has failed (e.g., Liberty et al., 1999; Musil et al., 2002).

One factor that limits the resolution of crosswell seismic tomography is angular coverage (e.g., Michelena, 1993; Rector and Washbourne, 1994). The areas at the top and bottom of tomograms are constrained almost entirely by near-horizontal rays, so lateral variations in subsurface structure are smeared out. Several synthetic studies (e.g., Curtis, 1998) have shown that angular coverage (and therefore resolution) can be improved by including traveltimes from borehole sources to surface geophones. In field studies, however, including borehole-to-surface traveltimes has resulted in significant artifacts, such as spurious lateral-velocity variations (e.g., Squires et al., 1992, 1994; Bernabini and Cardarelli, 1997). The inclusion of borehole-to-surface information in crosswell to-

Manuscript received by the Editor April 21, 2004; revised manuscript received June 6, 2005; published online May 24, 2006.

${ }^{1}$ Formerly Boise State University, Center for Geophysical Investigation of the Shallow Subsurface, Boise, Idaho 83725; presently Pennsylvania State University, Department of Geosciences, University Park, Pennsylvania 16802. E-mail: gmoret@ geosc.psu.edu.

${ }^{2}$ Boise State University, Center for Geophysical Investigation of the Shallow Subsurface, Boise, Idaho 83725. E-mail: mknoll@cgiss.boisestate.edu; wbarrash@cgiss.biosestate.edu; billc@cgiss.boisestate.edu.

(C) 2006 Society of Exploration Geophysicists. All rights reserved. 
mography is complicated by the fact that $\mathrm{P}$-wave velocities in nearsurface materials can change by an order of magnitude over a few meters (Miller and Xia, 1998). It is difficult for regularized tomographic inversions to reproduce such extreme velocity changes.

In this study, we used crosswell seismic tomography to investigate the sedimentary architecture between wells at the Boise Hydrogeophysical Research Site (BHRS), a research wellfield in coarse, unconsolidated alluvial deposits. We paid careful attention to data quality and the choice of inversion parameters and used several methods to evaluate our results. By including borehole-tosurface traveltimes in addition to crosswell coverage we were able to eliminate an $\mathrm{X}$-shaped inversion artifact from the tomogram. $\mathrm{Al}$ though the methods that we employed have been described elsewhere, the combination of these methods has never before been used to analyze a near-surface crosswell seismic data set. The final seismic velocity image agrees well with previous stratigraphic studies conducted at the site (Barrash and Clemo, 2002; Barrash and Reboulet, 2004).

\section{FIELD EXPERIMENT}

\section{Field site}

The BHRS consists of 18 wells in a shallow, unconfined aquifer near Boise, Idaho (Figure 1). The aquifer at the BHRS consists of an approximately 20 -m-thick layer of coarse alluvial sediments underlain by clay and basalt. These sediments are chiefly cobble-andsand deposits with some sand lenses. The BHRS was designed as a testing ground for geophysical and hydrologic methods with the near-term goal of developing geophysical methods to predict hydraulic conductivity (Barrash et al., 1999). As Figure 1 shows, 13 wells have been emplaced to support thorough characterization of a control volume of about 20-m diameter and 20-m depth with well

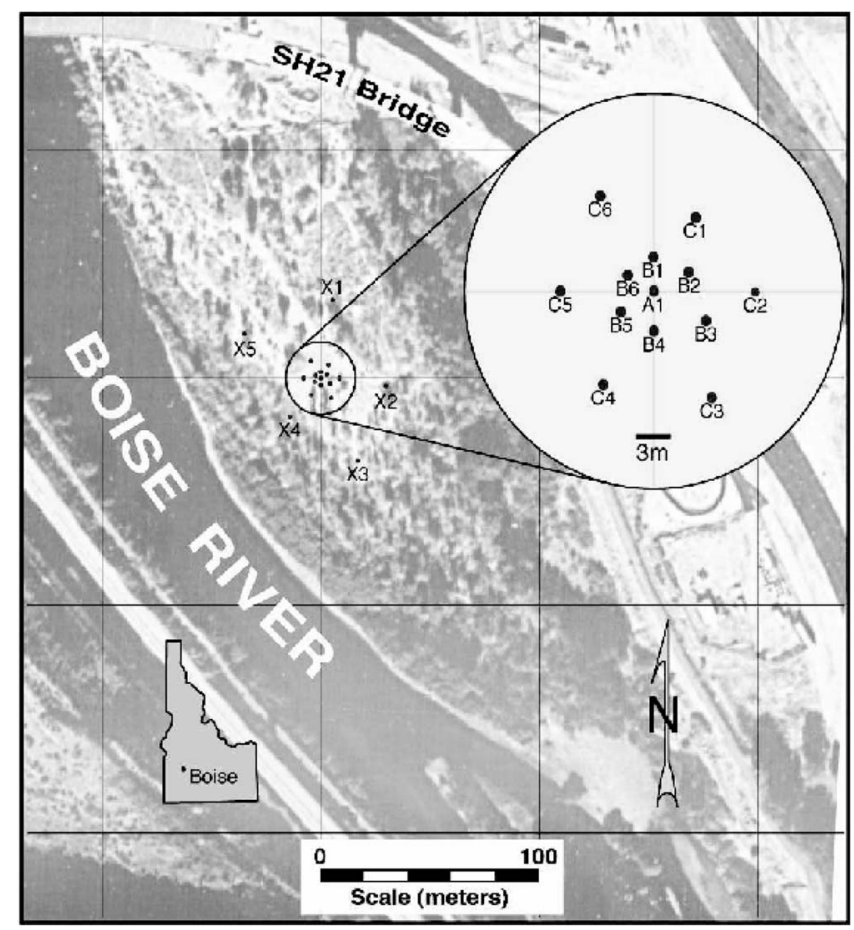

Figure 1. Aerial photograph, map, and well field layout of the Boise Hydrogeophysical Research Site.
A1 in the center. The wells in the central area consist of an inner ring roughly $3 \mathrm{~m}$ from A1 (wells B1-B6), and an outer ring between 7 and $10 \mathrm{~m}$ from A1 (wells C1-C6). There is also a set of boundary wells 22 to $43 \mathrm{~m}$ from A1 (wells X1-X5). All of these wells were drilled to a depth of $\sim 20 \mathrm{~m}$ and cased with 4-in PVC well screen. Special care was taken during well completion to minimize the disturbance of the formation surrounding the holes. The finished well site is suitable for surface, surface-to-borehole, and crosswell geophysics, as well as a wide variety of hydrologic tests (Barrash et al., 1999; Clement et al., 1999).

Five stratigraphic units have been identified in the central area of the site (Figure 2) based on the analysis of neutron porosity logs (Barrash and Clemo, 2002), grain size distributions in core samples (Barrash and Reboulet, 2004), and ground-penetrating radar reflection profiles (Peretti et al., 1999). Units 1 and 3 are low porosity (mean porosities of 0.18 and 0.17 , respectively) cobble-and-sand deposits. Units 2 and 4 are higher porosity (mean porosities of 0.24 and 0.23 , respectively) cobble-and-sand deposits, with more variation in porosity values than Units 1 and 3 . Unit 5 is a channel sand at the top of the section in the western part of the BHRS. While the lithologic contrasts between the cobble-and-sand units are subtle (Barrash and Reboulet, 2004) their hydrologic properties (e.g., permeability distribution and tracer transport behavior) are significantly different (Barrash et al., 2003).

\section{Data collection}

We collected crosswell seismic data between wells $\mathrm{C} 1$ and $\mathrm{C} 4$ at the BHRS (Figure 1). These wells were chosen to characterize the change in sedimentary architecture in a cross section, oriented roughly perpendicular to the Boise River. Well A1 is located between wells $\mathrm{C} 1$ and $\mathrm{C} 4$, providing independent information about the material properties and sedimentary structure in the tomographic imaging plane. Because the wells are nearly as far apart $(17.1 \mathrm{~m})$ as they are deep $(20.1 \mathrm{~m}$ and $20.9 \mathrm{~m}$, respectively), the angular coverage of the crosswell data is poor.

We used a borehole sparker as a seismic source, and we used a hydrophone string and surface geophones as receivers. The resulting signals were recorded on a 48-channel engineering seismograph using a sample interval of $0.0625 \mathrm{~ms}$. We planted 11 geo-

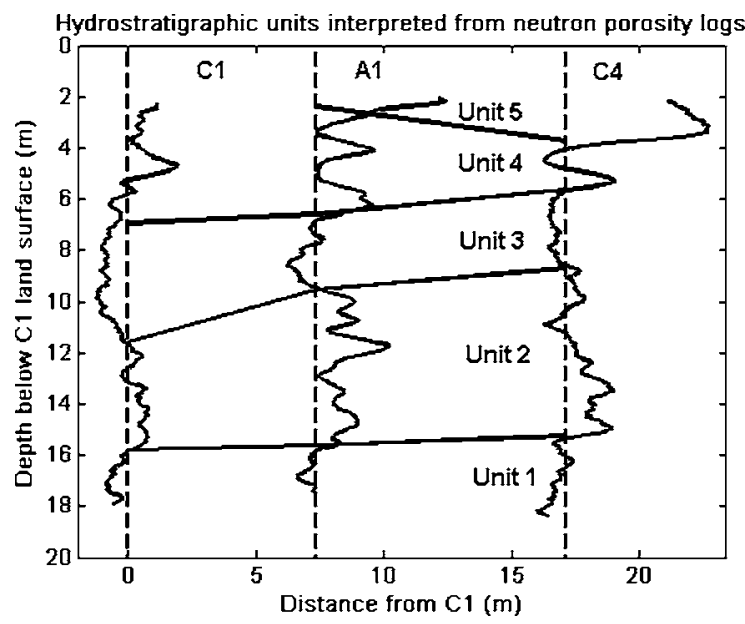

Figure 2. Interpreted porosity units in the $\mathrm{C} 1-\mathrm{C} 4$ plane. The verti$\mathrm{cal}$ dashed lines are the well locations and also represent 0.20 on the porosity logs. Unit 5 is not present in the $\mathrm{C} 1$ porosity $\log$. 
phones $1.0 \mathrm{~m}$ apart along the surface between the wells and buried them several centimeters deep to improve the signal-to-noise (S/N) ratio. The shots were fired in well $\mathrm{C} 1$ at $0.1-\mathrm{m}$ intervals from just below the water table (1.95-m depth) to the bottom of the well while the hydrophone string was in well $\mathrm{C} 4$. The 32 active hydrophones had a spacing of $0.5 \mathrm{~m}$, and we raised the string $0.1 \mathrm{~m}$ five times, repeating the sparker shots for each new hydrophone position. This provided an effective hydrophone spacing of $0.1 \mathrm{~m}$. We also moved the geophones and fired the sparker at $0.1-\mathrm{m}$ intervals in well $\mathrm{C} 4$ to obtain traveltimes between $\mathrm{C} 4$ and the surface.

Figure 3 shows the crosswell and borehole-to-surface traces from a shot gather collected with the sparker at roughly $10-\mathrm{m}$ depth in $\mathrm{C} 1$. Figure 4 shows the power spectra for the same traces. The relative power of the crosswell traces decreases at frequencies higher than approximately $\sim 1200 \mathrm{~Hz}$. As the average seismic velocity at the BHRS is $\sim 2400 \mathrm{~m} / \mathrm{s}$, the wavelength of the transmitted energy is $\sim 2 \mathrm{~m}$. The relative power of the borehole-to-surface traces decreases sharply at frequencies higher than $\sim 500 \mathrm{~Hz}$, sug-
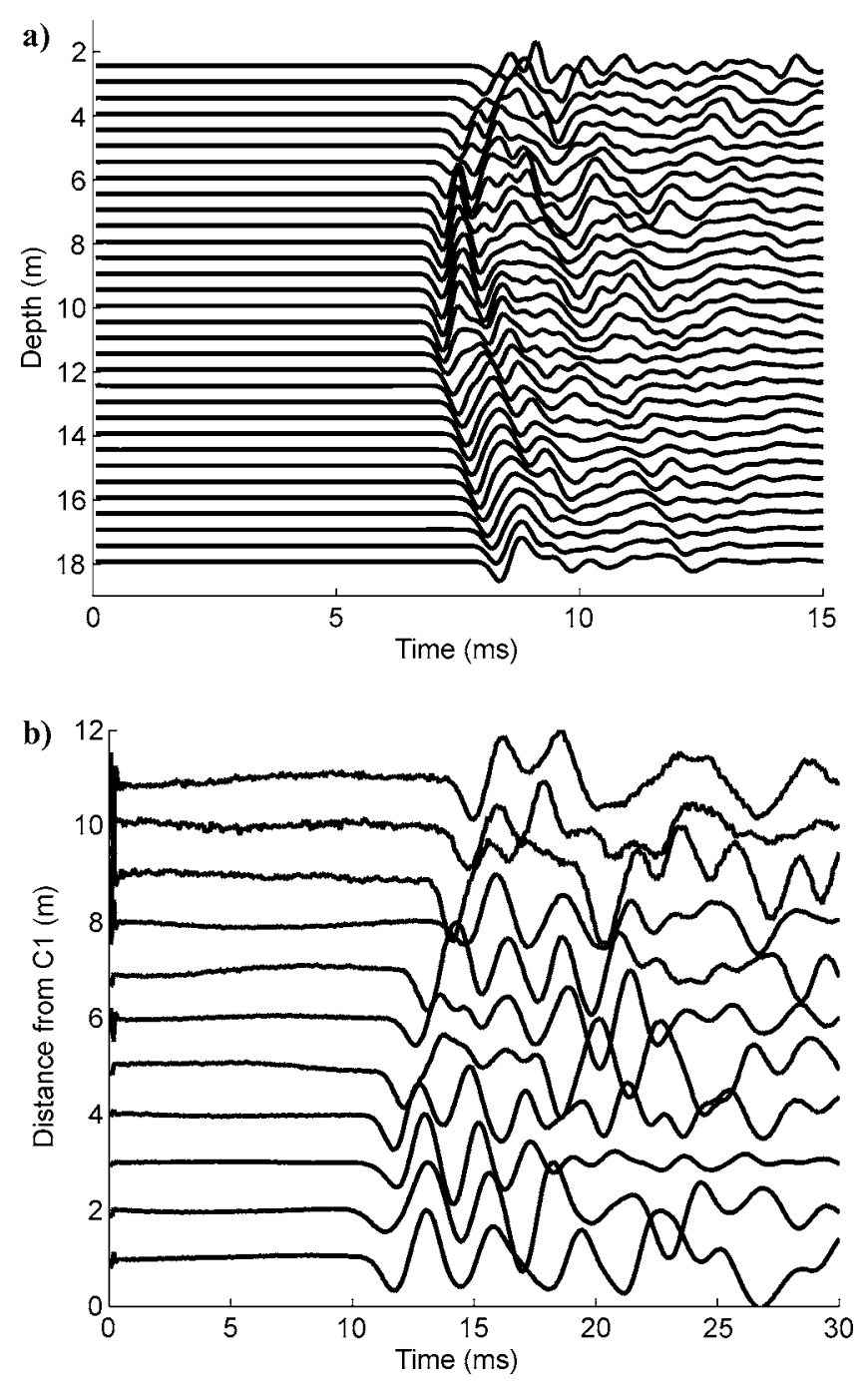

Figure 3. (a) Crosswell traces and (b) borehole-to-surface traces for a shot gather with the sparker in well $\mathrm{C} 1$ at $8.3-\mathrm{m}$ depth and the hydrophones in well C4. The traces are individually gained. Notice that the two figures have different time scales. gesting that the vadose zone is more attenuative than the saturated zone. The S/N ratio of the borehole-to-surface data is also much lower than for the crosswell data.

We picked the first arrivals by hand, using an interactive picking and display program that interpolated the waveform between samples. The minimum uncertainty in these traveltimes is one-half of a sample interval (approximately $0.03 \mathrm{~ms}$ ). With the high frequency, high $\mathrm{S} / \mathrm{N}$ crosswell data, the uncertainty because of traveltime picking may approach this minimum threshold. The borehole-tosurface data are noisier and lower frequency, so we would expect the traveltime picking errors to be larger.

\section{Well deviation}

Corrections for well deviation are crucial to the success of crosswell tomography (Maurer, 1996; Peterson, 2001). We measured the well deviation using magnetic deviation logs. Magnetic deviation logs include a three-axis magnetometer and two accelerometers, and can be used to estimate the $x$ and $y$ deviations of the wells at different depths. Deviated wells result in a $3 \mathrm{D}$ problem, so the well deviation cannot be fully accounted for in 2D tomography. We chose to project the well deviations onto the vertical plane between the two wells. At every source and receiver position, the component of the well deviation at that depth lying in the plane was added to the $x$-coordinate of the position. The deviations for each depth were determined by linear interpolation between the two nearest deviation measurements. The out-of-plane component of the deviation was ignored. With two wells $17.1 \mathrm{~m}$ apart at the surface, if one of the wells is $1 \mathrm{~m}$ out of plane, the difference in pathlength will be $.03 \mathrm{~m}$, which, in a medium with a seismic velocity of $2400 \mathrm{~m} / \mathrm{s}$, would result in a traveltime error of $.012 \mathrm{~ms}$, or onefifth of a sample interval.

The main source of error in the horizontal positions is the uncertainty in the deviation logs, which are accurate to within $0.5^{\circ}$ inclination. A $0.5^{\circ}$-inclination error translates into a positioning error that increases from zero at the surface to $0.16 \mathrm{~m}$ at $18-\mathrm{m}$ depth. In a medium with a seismic velocity of $2400 \mathrm{~m} / \mathrm{s}$, a $0.16-\mathrm{m}$ positioning error will result in a $0.064-\mathrm{ms}$ traveltime error, which is slightly greater than one sample interval. Thus, the uncertainty in the de-

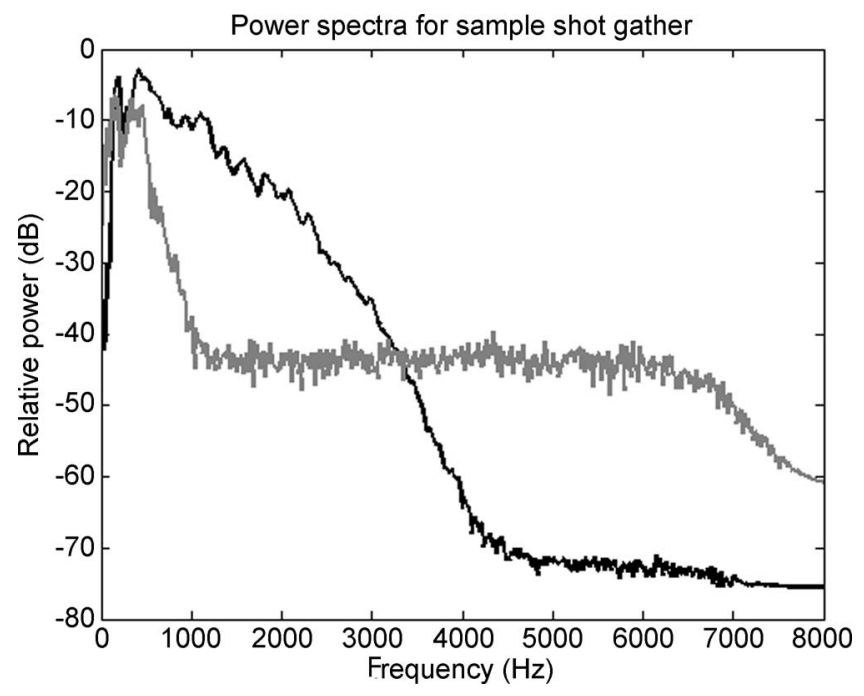

Figure 4. Average power spectra for the crosswell (black line) and borehole-to-surface (gray line) traces shown in Figure 3. 
viation logs results in traveltime errors of roughly the same magnitude as the uncertainty in the first arrivals of the crosswell data.

\section{Quality control}

Quality control (QC) plots are commonly used to assess the reliability of crosswell tomography data prior to inversion (Gheslagni and Santamarina, 1998; Peterson, 2001; Tronicke et al., 2002). For example, Figure 5 shows a plot of the apparent velocity versus angle for the crosswell data. Apparent velocity is the straight-line distance between source and receiver divided by the traveltime, while the angle is the angle of the line from the horizontal. The average apparent velocity changes as a function of angle if there are systematic errors in the traveltimes or source and receiver positions, or if anisotropy is present. As shown in Figure 5, the apparent velocities are more variable near zero degrees. The variability is increased because the near-horizontal rays sample the velocity of individual stratigraphic units, while the steeper rays average the velocities of all the units they travel through. There are also many low apparent velocities at negative angles, suggesting that there may be a low-velocity layer near the water table. The average apparent velocity does not appear to change systematically as a function of angle, however, which suggests that the traveltime data do not contain systematic errors and the subsurface at the BHRS does not exhibit significant P-wave velocity anisotropy.

\section{TOMOGRAPHIC INVERSION}

Although we collected data with a source and receiver spacing of $0.1 \mathrm{~m}$, we did not use all of the data in the final inversions. The resolution of crosswell tomography is generally limited by the angular coverage (Michelena, 1993; Rector and Washbourne, 1994), so using more traveltimes does not improve the resolution. Yoshizawa and Kennett (2002) used Fresnel zones to show that arrivals at receivers located less than one-sixth of a wavelength apart contain equivalent information. Using more traveltimes does reduce the sensitivity of the inversion to traveltime errors, but it also increases the computational time required by the inversion. We performed tests (not shown) with different source and receiver spac-

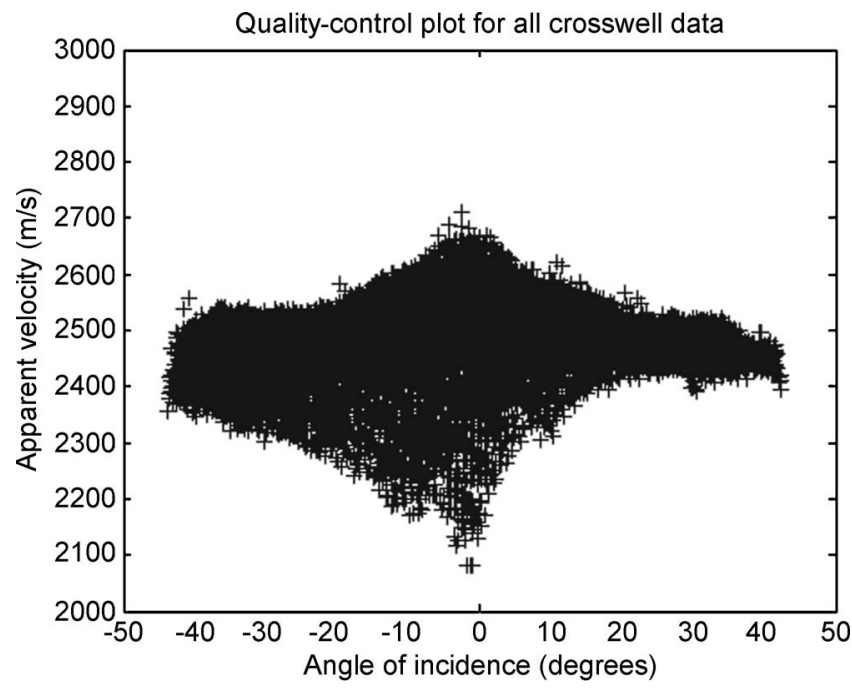

Figure 5. Apparent velocity as a function of angle. Negative angles correspond to traveltimes recorded with the source below the receiver. ings and found that, for the inversion parameters we chose, there were only small differences between the velocity model produced using the entire data set (26,560 crosswell traveltimes) and the velocity model produced using a crosswell source and receiver spacing of $0.5 \mathrm{~m}$ (1088 crosswell traveltimes). We chose to use the additional data to compare inversion results for different subsets of the data (described later). All of the results in this paper have been produced using a crosswell source and receiver spacing of $0.5 \mathrm{~m}$. Using fewer traveltimes allowed us to invert the data many times with different inversion parameters. We also used an effective source spacing of $0.5 \mathrm{~m}$ for the borehole-to-surface data, resulting in a total of 661 traveltimes.

We inverted the $\mathrm{C} 1-\mathrm{C} 4$ data set using a tomography algorithm based on Aldridge and Oldenburg (1993). The algorithm, which we implemented in Matlab, is an iterative nonlinear inversion that uses a finite-difference approximation to the eikonal equation as a forward model and ray-tracing to generate the Jacobian (or Frechet) matrix. The routine minimizes the objective function (Aldridge and Oldenburg 1993):

$$
\Phi(\Delta \mathbf{s})=\left\|\mathbf{W}_{d}(\mathbf{J} \Delta \mathbf{s}-\Delta \mathbf{t})\right\|^{2}+\lambda^{2}\left\|\mathbf{W}_{m}\left(\mathbf{s}+\Delta \mathbf{s}-\mathbf{s}_{\text {ref }}\right)\right\|^{2}
$$

In equation $1, \mathbf{s}$ is the slowness model, $\mathbf{s}_{\mathbf{r e f}}$ is the reference slowness model (also used as the starting model), $\Delta \mathbf{s}$ is the slowness model update at a given iteration, and $\mathbf{J}$ is the Jacobian matrix. The difference between the measured traveltimes and the forwardmodeled traveltimes is $\Delta \mathbf{t}$. The parameter $\lambda$ controls the trade-off between fitting the data equations and fitting the constraint equations. The matrix $\mathbf{W}_{d}$ contains the data weights, and the matrix $\mathbf{W}_{m}$ contains the constraint equations.

\section{Grid sizes}

Our tomography routine uses different fixed-grid sizes for forward modeling and inversion, an approach previously described by Ammon and Vidale (1993) and Lanz et al. (1998). We can therefore choose the optimum grid size for the forward model without considering the effect on the inversion, and vice versa. In this paper, we will refer to the use of separate grids for forward modeling and inversion as a two-grid inversion, which is not to be confused with multiscale inversion (e.g., Zhou, 2003).

The forward-model grid size should be small enough that numerical errors in the forward modeling are significantly less than the errors in the traveltime data. We found that a forward-model grid of $0.25-\mathrm{m}$ square cells allows the inversion to converge to solutions with rms traveltime misfits that are close to the estimated minimum traveltime errors.

The choice of a grid size for the inversion is a trade-off between uncertainty and resolution. Large grid sizes result in high ray densities for individual grid cells, so the velocity model is less sensitive to traveltime errors, but they also result in low resolution. Lanz et al. (1998) suggest using a grid size of roughly a wavelength. Calculations of wave-propagation effects (e.g., Williamson and Worthington, 1993; Schuster, 1996) show that the true resolution of the data is greater than a wavelength. As Zhou (2003) points out, however, if a large grid size is used, then velocity contrasts that occur in the middle of grid cells cannot be accurately imaged. We chose to use an inverse model grid of 1-m square cells, roughly a half-wavelength across. 
We compared the two-grid inversion scheme to single-grid inversions with grid sizes of $0.25 \mathrm{~m}$ and $1.0 \mathrm{~m}$. The rms traveltime error was $0.038 \mathrm{~ms}$ for the two-grid inversion, $0.049 \mathrm{~ms}$ for the $1.0-\mathrm{m}$ grid, and $0.025 \mathrm{~ms}$ for the $0.25-\mathrm{m}$ grid. The two-grid inversion and the $1.0-\mathrm{m}$ single-grid inversion use the same inverse parameterization, so the higher rms error for the single-grid version is solely because of the less accurate forward model. We can also evaluate grid size choice using ray density plots. For each cell in the velocity model, the ray density is the sum of the lengths of the raypaths through the cell normalized by the width of the cell. The ray density plot for the 0.25 -m grid (Figure 6a) shows that many of the rays are channeled into a few cells. However, the ray density plot generated using the two-grid inversion (Figure 6b) does not contain these features. We chose to use the two-grid inversion because it results in more accurate forward modeling than the use of a single larger grid and avoids the ray-channeling caused by the use of a single smaller grid.

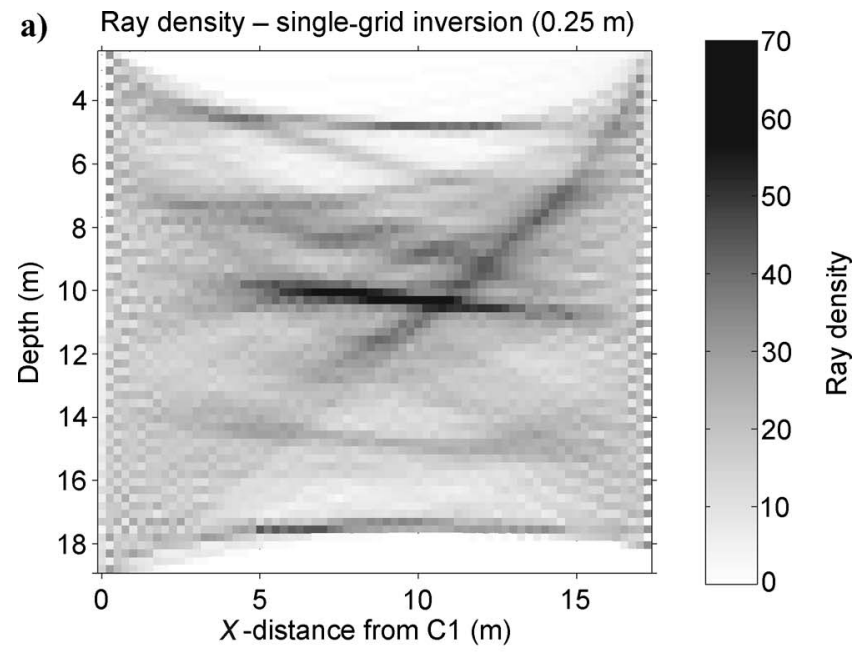

b) Ray density - two-grid inversion ( $0.25 \mathrm{~m}$ and $1 \mathrm{~m})$

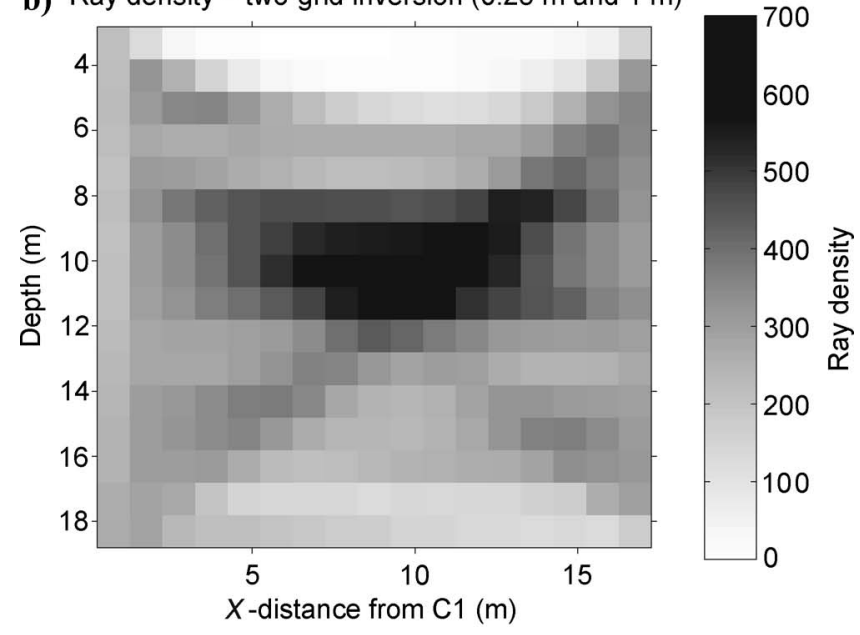

Figure 6. Ray density plots for the $\mathrm{C} 1-\mathrm{C} 4$ crosswell data inverted with (a) a single $0.25-\mathrm{m}$ grid and (b) a forward grid of $0.25 \mathrm{~m}$ and an inverse grid of $1 \mathrm{~m}$. The channels of high ray density in the single-grid plot are an indication that the inversion is not functioning properly. Both inversions were performed with a constant velocity starting model.

\section{Regularization parameters}

The regularization scheme we used minimizes both the vertical and horizontal first derivatives of the slowness model and the difference between the slowness model and the reference model. The matrix of constraint equations has the form

$$
\mathbf{W}_{m}=\left[\begin{array}{c}
\mathbf{D}_{\mathbf{h}} \\
\alpha_{1} \mathbf{D}_{\mathbf{v}} \\
\alpha_{2} \mathbf{D}_{\mathbf{0}}
\end{array}\right],
$$

where the equations in $\mathbf{D}_{\mathbf{h}}$ constrain the horizontal first derivative of the slowness model, the equations in $\mathbf{D}_{\mathbf{v}}$ constrain the vertical first derivative of the slowness model, and the equations in $\mathbf{D}_{\mathbf{0}}$ constrain the difference between the slowness model and the reference slowness model. We chose an $\alpha_{1}$ value of 0.1 because geostatistical analyses of sedimentary deposits similar to those at the BHRS typically show much greater correlation lengths in the horizontal direction than in the vertical direction (e.g., Jussel et al., 1994a). We experimented with a range of values for $\alpha_{2}$. The value we chose (0.05) produces geologically reasonable results and represents roughly the same ratio of damping to smoothing used by Lanz et al. (1998).

The L-curve (e.g., Hansen, 1992) is a useful tool for evaluating the trade-off between fitting the data and fitting the constraint equations when the data error is unknown. The L-curve is a plot of data misfit vs. constraint equation misfit, and is so-named because it tends to form an L shape. The $\lambda$ value at the corner of the L-curve is the optimum value because it produces low values for both types of misfit. Figure 7 shows the L-curve produced by 14 inversions of the $\mathrm{C} 1-\mathrm{C} 4$ tomography data using different values of $\lambda$. The corner of the curve is not sharp, so several different $\lambda$ values represent reasonable trade-offs. The $\lambda$ value we chose (200) results in a rms traveltime residual of $0.0597 \mathrm{~ms}$. This rms residual seems reason-

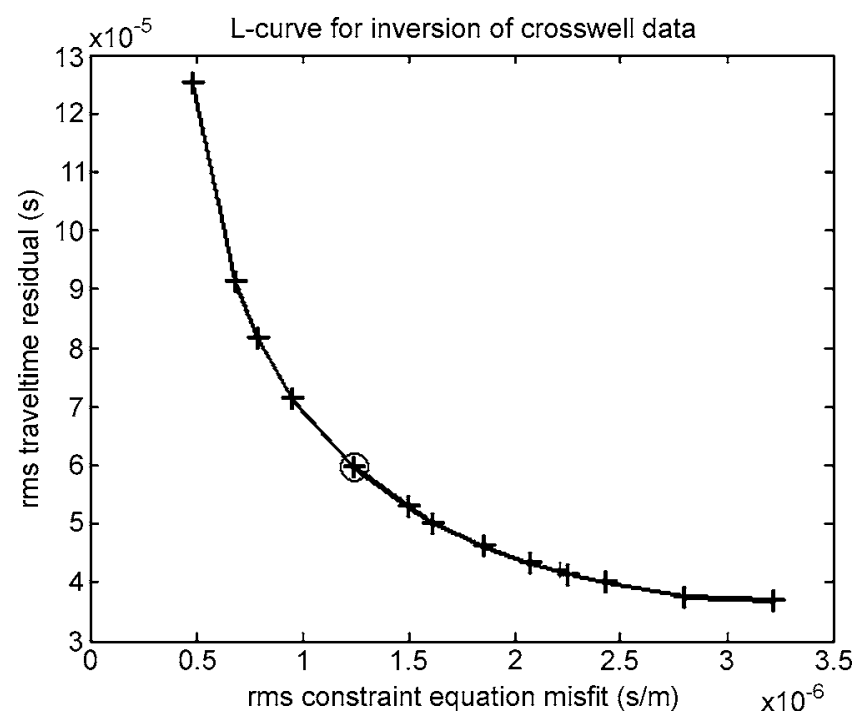

Figure 7. L-curve for tomographic inversion of the C1-C4 crosswell data using different $\lambda$ values. The $\lambda$ values range from 1000 at the top right to 20 at the bottom left. The circled point, the closest to the corner of the curve, corresponds to a $\lambda$ value of 200 . 
able, given our estimates of the minimum picking error $(0.03 \mathrm{~ms})$ and the maximum traveltime errors associated with the welldeviation uncertainty $(0.064 \mathrm{~ms})$

\section{Including borehole-to-surface traveltimes}

When we included the borehole-to-surface traveltimes in the inversion, the resulting tomograms contained unrealistic structures and velocities. The data constrain the low-velocity near-surface zone poorly, so the inversion fits the borehole-to-surface traveltimes by including spurious lateral velocity variations. Previous studies eliminated these artifacts by making static corrections (Squires et al., 1992, 1994) or using variable damping (Bernabini and Cardarelli, 1997). We eliminated them by using a starting and reference model based on prior information. Surface seismic refraction surveys at the BHRS show that the vadose zone P-wave velocity is roughly $300 \mathrm{~m} / \mathrm{s}$ (personal communication). We determined the thickness of the vadose zone $(1.95 \mathrm{~m})$ from water level measurements in wells $\mathrm{C} 1$ and $\mathrm{C} 4$ (the water levels in the two wells differed by less than a centimeter). While the capillary fringe in the aquifer may rise slightly above the water level in the wells, the difference is likely just a few centimeters in the coarse sediments at the BHRS (e.g., Dingman, 1994). Our forward model smears cell velocities over $0.25 \mathrm{~m}$, so we chose not to alter the water-table position to account for the effect of the capillary fringe.

We found that the inversion results were improved further by weighting the crosswell data more heavily than the borehole-tosurface data. The borehole-to-surface data are noisier because they have traveled through the high-attenuation vadose zone, which lowers the $\mathrm{S} / \mathrm{N}$ ratio and the peak frequency of the first arrivals. The surface geophones are also more susceptible to noise (e.g., wind, footsteps, traffic) than the downhole hydrophones. When the data were equally weighted, the rms crosswell traveltime residual was $0.058 \mathrm{~ms}$, while the rms borehole-to-surface traveltime residual was $0.184 \mathrm{~ms}$ (roughly three times greater). This difference implies that the borehole-to-surface traveltime errors are more than three times as great as the crosswell errors, because the tomography algorithm overfits the high-noise data when the data are equally weighted. We found that weighting the borehole-to-surface data one-tenth as heavily as the crosswell data produced good results. Given the low S/N ratio and low-frequency content of the borehole-to-surface traces in Figure 3 , it seems reasonable that their traveltime uncertainties would be an order of magnitude higher than those of the crosswell data.

The L-curve plot for the inversion of the crosswell and boreholeto-surface data using different data weights (not shown) did not have a distinct $\mathrm{L}$ shape (the rms traveltime residual decreased linearly with increasing constraint equation misfit). We chose to use the same $\lambda$ value (200) that we used to invert the crosswell data. Inverting the data using this $\lambda$ value resulted in a weighted rms traveltime residual of $0.205 \mathrm{~ms}$, more than three times higher than the crosswell traveltime residual. We would expect the residual to be higher because we have added more data without changing the number of parameters. While the number of traveltimes has increased by only $61 \%$, the increased angular coverage of the borehole-to-surface data constrains the velocity variation far more than a similar increase in the number of crosswell traveltimes would, so the large increase in the residual seems reasonable.

\section{SOLUTION APPRAISAL}

\section{Dependence on starting model}

Nonlinear inverse problems such as curved-ray seismic tomography are sensitive to the starting model used. Vasco et al. (1996) performed 1075 inversions of a crosswell seismic data set and used cluster analysis to show that the resulting solutions fell into 61 distinct groups, each corresponding to a separate local minimum of the objective function. A more qualitative approach is to compare inversion results from small numbers of starting models to assess which regions of the final model are well resolved by the data (e.g., Lanz et al., 1998). We inverted the crosswell data using three different starting models: 1) a uniform model with a velocity of $2400 \mathrm{~m} / \mathrm{s}$; 2) a constant vertical gradient model with a velocity ranging from $2000 \mathrm{~m} / \mathrm{s}$ at the surface to $2500 \mathrm{~m} / \mathrm{s}$ at $20-\mathrm{m}$ depth; and 3) a constant horizontal gradient model with a velocity ranging from $2000 \mathrm{~m} / \mathrm{s}$ at well $\mathrm{C} 1$ to $2500 \mathrm{~m} / \mathrm{s}$ at well C4.

Figure 8 shows the final velocity models produced by inverting the crosswell data using these starting models. The velocity models produced using the uniform (a) and vertical gradient (b) starting models are quite similar at depths between $5 \mathrm{~m}$ and $17 \mathrm{~m}$. The largest differences between the models occur at the top and bottom of the image, suggesting that the velocities in these regions are poorly constrained by the data. The velocity model produced using the horizontal gradient starting model (c) contains roughly the same horizontal velocity gradient as the starting model, which indicates that crosswell tomography poorly resolves lateral changes in velocity.

As discussed above, the starting models used to invert the crosswell and borehole-to-surface data were identical to those used to invert the crosswell data alone except that the velocity above the water table was changed to $300 \mathrm{~m} / \mathrm{s}$. Once again, the inversion results using the uniform and vertical gradient starting models are similar to each other between the depths of $5 \mathrm{~m}$ and $17 \mathrm{~m}$ (Figure 9). The top and bottom of the image are poorly constrained by the a)

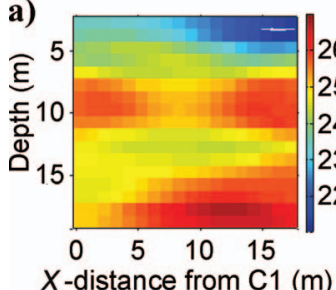

c)

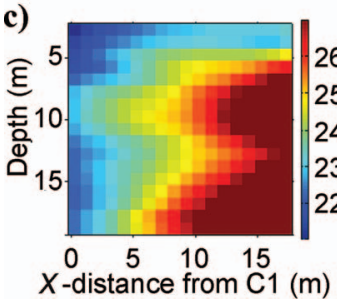

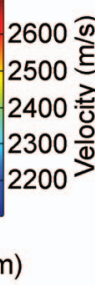

b)

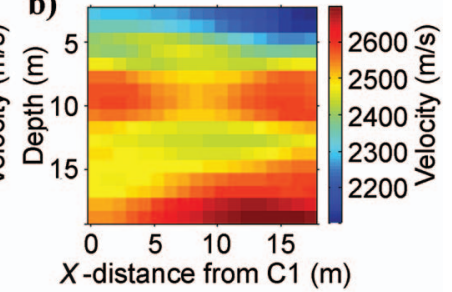

d)

d)

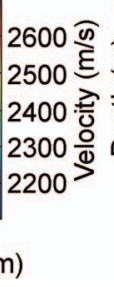

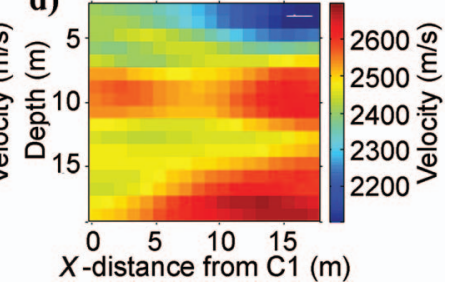

Figure 8. A comparison of tomograms produced by inverting the C1-C4 crosswell data with three different starting models: (a) a uniform velocity of $2400 \mathrm{~m} / \mathrm{s}$; (b) a vertical gradient model with a velocity of $2000 \mathrm{~m} / \mathrm{s}$ at the surface and $2500 \mathrm{~m} / \mathrm{s}$ at 20-m depth; (c) a lateral gradient model with a velocity of $2000 \mathrm{~m} / \mathrm{s}$ at well C1 and $2500 \mathrm{~m} / \mathrm{s}$ at well C4. Figure (d) is the tomogram produced using a different set of traveltimes with all shot and receiver locations $0.3 \mathrm{~m}$ lower than those used to produce tomograms (a) to (c). 
data. The velocity model produced using the horizontal gradient starting model has a large horizontal velocity gradient itself. This observation is consistent with our finding that the borehole-tosurface data cannot be successfully included in the inversion without a starting model derived from prior information.

\section{Ray density}

Ray density plots can be used to assess the reliability of tomographic images. Model velocities are more reliable in cells constrained by many rays than in cells constrained by fewer rays.

Figure $6 \mathrm{~b}$ shows the ray density plot for the crosswell inversion. Because we chose a relatively large-grid size for the inverse model, most of the pixels are constrained by a large number of rays, reducing the influence of both traveltime noise and the starting model. Most of the pixels have ray densities greater than 50. These high ray densities justify our choice to use only a fraction of the crosswell data. The ray density is lowest at the top and bottom of the image, where the differences between inversion results from different starting models showed that the cell velocities were poorly constrained.

Figure 9d shows the ray density plot for the inversion that included both the crosswell data and the borehole-to-surface data. We have weighted the borehole-to-surface rays 0.1 times as heavily as the crosswell rays in this plot to reflect the reduced weighting of these rays in the inversion. The ray density plot in Figure $9 \mathrm{~d}$ is similar to the crosswell ray density plot in Figure $6 \mathrm{~b}$ in that the densities are lowest above 5-m depth and below 17-m depth. The ray density is particularly low in the vadose zone because the vadose zone is traversed only by the less heavily weighted boreholeto-surface rays.
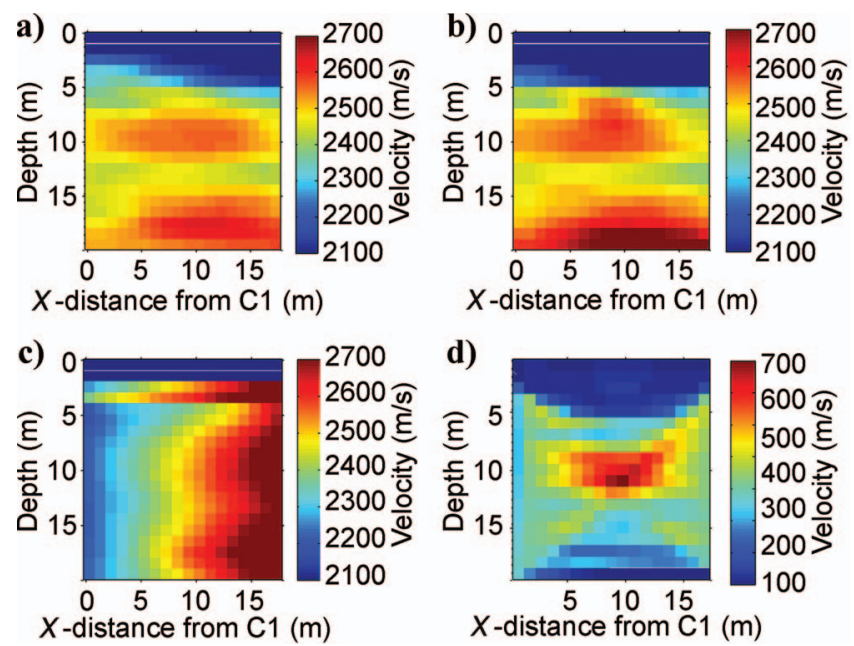

Figure 9. A comparison of tomograms produced by inverting the C1-C4 crosswell and borehole-to-surface data with three different starting models: (a) a uniform velocity of $2400 \mathrm{~m} / \mathrm{s}$ with a $300 \mathrm{~m} / \mathrm{s}$ vadose zone, (b) a vertical gradient model with a velocity of $2000 \mathrm{~m} / \mathrm{s}$ at the surface and $2500 \mathrm{~m} / \mathrm{s}$ at $20-\mathrm{m}$ depth and a $300-$ $\mathrm{m} / \mathrm{s}$ vadose zone, (c) a lateral gradient model with a velocity of $2000 \mathrm{~m} / \mathrm{s}$ at well C1 and $2500 \mathrm{~m} / \mathrm{s}$ at well C4 and a $300-\mathrm{m} / \mathrm{s}$ vadose zone. Figure (d) shows the ray density plot for tomogram (a). The velocity scale in tomograms (a) to (c) has been clipped at $2100 \mathrm{~m} / \mathrm{s}$ for easy comparison to Figure 8. In each of the tomograms, the velocity above the water table is within $10 \mathrm{~m} / \mathrm{s}$ of the starting model.

\section{Model covariance matrix}

Another way to assess the reliability of inversion results is to evaluate the model covariance matrix (e.g., Menke 1984), which relates uncertainty in the data and the constraint equations to uncertainty in the inversion result. The diagonal elements of the model covariance matrix represent the variances of each parameter in the slowness model. In linearized inversions, these variances may not represent the full uncertainty in the inversion result (Tarantola and Valette, 1982; Alumbaugh, 2000), but they show how the local minimum of the objective function that is found by the inverse routine can change in response to errors in the data and constraint equations. For regularized inversion, the model covariance matrix (MCM) is given by (Alumbaugh and Newman, 2000)

$$
\mathbf{M C M}=\left[\left[\mathbf{W}_{d}^{*} \mathbf{J}^{f}\right]^{\mathrm{T}} \mathbf{W}_{d}^{*} \mathbf{J}^{f}+\lambda^{* 2} \mathbf{W}_{m}{ }^{T} \mathbf{W}_{m}\right]^{-1},
$$

where $\mathbf{J}^{f}$ is the Jacobian matrix for the final iteration, and $\mathbf{W}_{d}$ is the data weighting matrix. We assumed that our data errors were uncorrelated, so our $\mathbf{W}_{d}$ was a diagonal matrix with entries that were the reciprocals of the standard deviations of the uncertainties associated with each traveltime. The parameter $\lambda^{*}$ is the reciprocal of the standard deviation of the uncertainty in the constraint equations. Alumbaugh and Newman (2000) assume that choosing the optimal $\lambda$ value for the inversion is equivalent to estimating the value of $\lambda^{*}$. In general, $\mathbf{W}_{d}$ and $\lambda^{*}$ are rough estimates, so the MCM-derived uncertainties are not the true uncertainties of the model results. We used $6 \times 10^{-5} \mathrm{~s}$ as the standard deviation of the uncertainty in the crosswell traveltimes, a value that is near to both the sample interval of the data and the estimated traveltime error caused by borehole deviation uncertainty. We estimated the standard deviation of the uncertainty in the borehole-to-surface traveltimes to be ten times larger than the crosswell uncertainty (6 $\times 10^{-4} \mathrm{~s}$ ). Because we chose our optimal $\lambda$ value (200) while using a $\mathbf{W}_{d}$ that weighted the crosswell and borehole-to-surface data by 1 and 0.1 , respectively, we used a $\lambda^{*}$ value of 200 divided by the standard deviation of the uncertainty in the crosswell data.

Figure 10 shows the covariance-derived uncertainties, $\mathbf{u}_{i}$, for the tomograms in Figures 8a and 9a. Because MCM contains information about the slowness model, and we are interested in velocities, we calculated the uncertainties using

$$
\mathbf{u}_{i}=\frac{1}{2}\left(\frac{1}{s_{i}-\sqrt{\mathbf{M C M}_{i i}}}-\frac{1}{s_{i}+\sqrt{\mathbf{M C M}_{i i}}}\right) .
$$

All of the uncertainties are less than $10 \mathrm{~m} / \mathrm{s}$. Although these low uncertainties are approximations of the true uncertainties, they suggest that the tomograms are relatively insensitive to errors in the traveltimes and constraint equations.

In this study, we can test the predicted sensitivity of the inversion results to traveltime uncertainty by inverting a different subset of the large amount of field data collected. Figure 8d shows the tomogram produced by inverting data collected with each source and receiver position $0.3-\mathrm{m}$ lower than for the data used in the rest of this paper. Figure $8 \mathrm{~d}$ is almost identical to $8 \mathrm{a}$ (which was produced using the same starting model), suggesting that the low uncertainties predicted by MCM are reasonable. 


\section{Model resolution matrix}

The model resolution matrix (MRM) predicts how well individual model parameters can be resolved. For linear problems, MRM can be thought of as a filter that acts on the true model to produce the inversion results (Menke, 1984):

$$
\mathbf{s}=\mathbf{M R M} \mathbf{s}_{\text {true }} .
$$

The MRM of a linear problem depends only on the geometry of the problem, the assumed uncertainties, and the regularization used, so it can be calculated prior to any data acquisition. For linearized inversions such as ours, on the other hand, the MRM depends on the velocity model, so it cannot be calculated before performing the inversion. Assuming that the inversion result is close to the true slowness model, the MRM is given by (Alumbaugh and Newman, 2000):

$$
\mathbf{M R M}=\left[\left[\mathbf{W}_{d} \mathbf{J}^{f}\right]^{\mathrm{T}} \mathbf{W}_{d} \mathbf{J}^{f}+\lambda^{* 2} \mathbf{W}_{m}{ }^{T} \mathbf{W}_{m}\right]^{-1}\left[\mathbf{W}_{d} \mathbf{J}^{f}\right]^{\mathrm{T}} \mathbf{W}_{d} \mathbf{J}^{f}
$$

The diagonal entries of MRM contain information about how well the slowness of each grid cell can be resolved. If the diagonal entry of MRM corresponding to a particular grid cell is 1 , then the model slowness of the cell is influenced only by the true slowness of the cell. If the diagonal entry is less than 1, then the model slowness of the cell is also influenced by the slownesses of surrounding cells. Figures 11a and 11b plot the diagonal entries of MRM which correspond to cells in the inversion results that are produced using the crosswell data and the combined data set, respectively. All of the cells have diagonal entries in MRM with values of less than 1, but the entries with larger values correspond to better-resolved
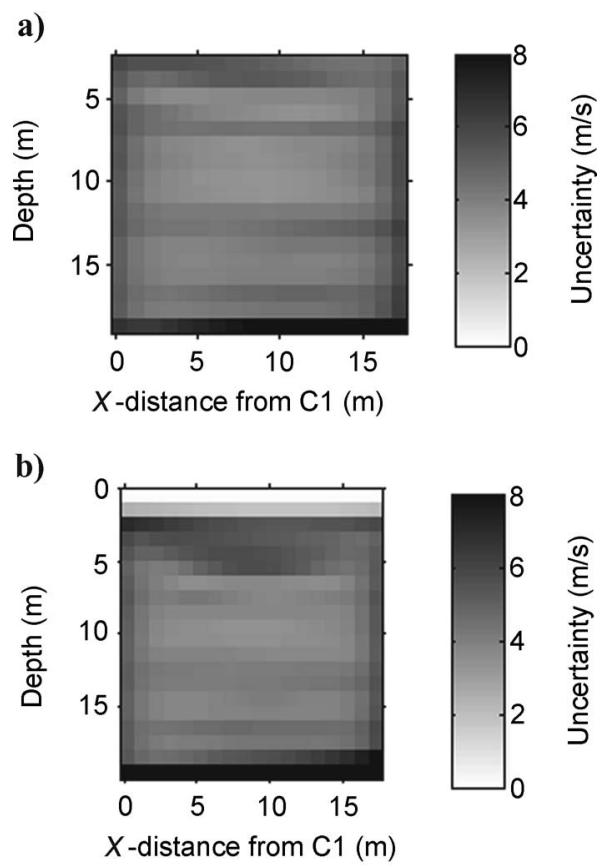

Figure 10. Estimated uncertainties in cell velocities because of uncertainties in the traveltimes and constraint equations for (a) the tomogram produced using crosswell data and (b) the tomogram produced using both crosswell and borehole-to-surface data. cells. The values fall to roughly half their maximum above $5 \mathrm{~m}$ and below $17 \mathrm{~m}$ in Figure 11a and above $6 \mathrm{~m}$ and below $17 \mathrm{~m}$ in Figure $11 b$; this suggests that the grid cell slownesses in these regions are poorly resolved.

We can further investigate the resolution of the inversion by examining the columns of MRM. Each column of MRM contains information about how the perturbation of one slowness parameter affects the slowness model. Thus, each column is a point-spread function that shows how the slowness model would change in response to a change in the slowness of a given grid cell. Figure 12 shows the point spread functions for a cell near the center of the tomograms in Figures 8a and 9a. For both cases, the perturbation results in a strong, positive change in the slownesses of cells that are horizontally aligned with the perturbed cell. Figure 10 shows that the horizontal first-derivative constraints result in a horizontal resolution of $\sim 5 \mathrm{~m}$ near the center of the tomogram. In contrast, the effect of the perturbation on the slownesses of cells that are vertically adjacent to the perturbed cell is small and negative. The vertical first derivative constraints are not weighted as heavily as the horizontal first derivative constraints, so the response of vertically adjacent cells is controlled by the traveltime equations, resulting in a negative change in slowness. Because this effect is relatively small, the vertical resolution of the inversion is $\sim 1 \mathrm{~m}$.

In interpreting these resolution estimates, it is important to remember that the true resolution of the problem is also limited by wave propagation effects (e.g., Williamson and Worthington, 1993; Schuster, 1996). Using the methods proposed by Schuster (1996), we found that the vertical resolution of our crosswell data at the center of the tomogram was $\sim 4 \mathrm{~m}$ and the horizontal resolution was $\sim 7 \mathrm{~m}$. These estimates may represent a worst-case scenario for tomographic resolution because, while arrivals from throughout the entire Fresnel zone contribute to the amplitude of the first arrival, the energy that contributes to the hand-picked first
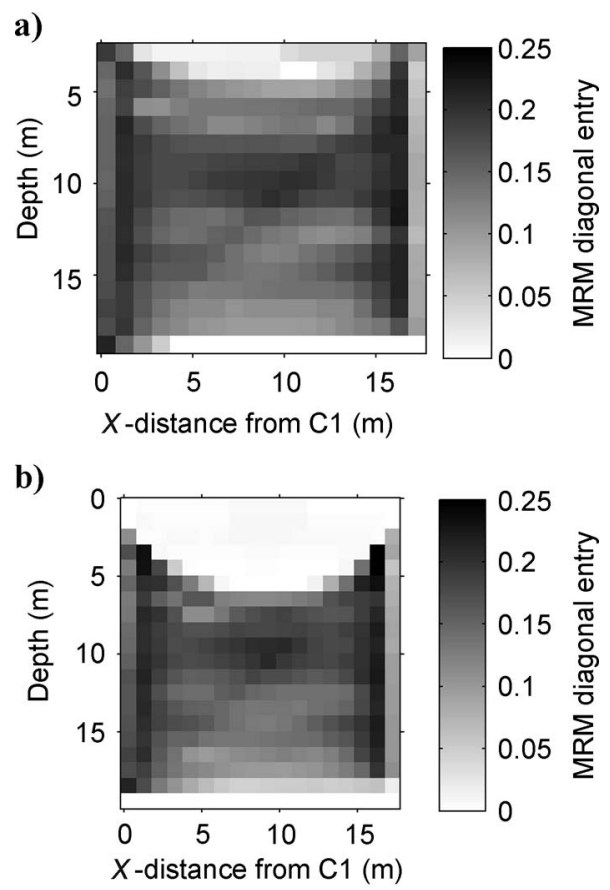

Figure 11. Diagonal entries of the model resolution matrices of (a) the tomogram produced using crosswell data and (b) the tomogram produced using both crosswell and borehole-to-surface data. 
break is less clearly defined. Because the MRM-estimated resolution is better than the resolution calculated using the method of Schuster (1996), we concluded that the resolution of the tomograms is limited by the resolution of the data rather than by the resolution of our inversion.

\section{RESULTS AND DISCUSSION}

Figures 13 and 14 show the tomograms produced without and with the borehole-to-surface data, respectively. Both tomograms have a generally layered structure, with a lower-velocity layer $(\sim 2400 \mathrm{~m} / \mathrm{s})$ down to a depth of $7 \mathrm{~m}$, a higher-velocity layer $(\sim 2600 \mathrm{~m} / \mathrm{s})$ between $7 \mathrm{~m}$ and $11 \mathrm{~m}$, a lower-velocity layer $(\sim 2400 \mathrm{~m} / \mathrm{s}$ ) between $11 \mathrm{~m}$ and $15 \mathrm{~m}$, and a higher-velocity layer $(\sim 2600 \mathrm{~m} / \mathrm{s})$ below $15 \mathrm{~m}$. Both tomograms also contain a region of low velocity $(\sim 2100 \mathrm{~m} / \mathrm{s})$ above $4-\mathrm{m}$ depth near well C4. In Figure 13, this low velocity region extends a few meters from C4; in Figure 14, it extends to well A1. The chief difference between the tomograms in the two figures is that the tomogram produced using only crosswell data (Figure 13) is smeared along the diagonals of the panel. This X-shaped pattern is most noticeable near the center of the panel, where the higher-velocity layer between $7 \mathrm{~m}$ and 11-m depth is interrupted by a slower zone $(\sim 2500 \mathrm{~m} / \mathrm{s})$.

\section{Comparison with neutron porosity log units}

Figures 13 and 14 also compare the tomograms to the stratigraphic units interpreted from neutron porosity logs and core (Barrash and Clemo, 2002; Barrash and Reboulet, 2004) as shown in
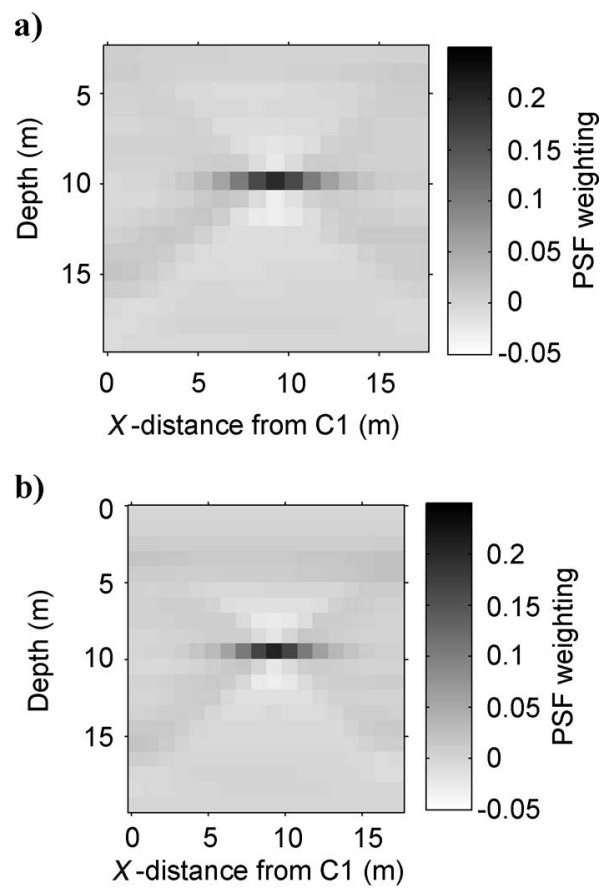

Figure 12. Point spread functions generated from the model resolution matrices of (a) the tomogram produced using crosswell data and (b) the tomogram produced using both crosswell and boreholeto-surface data. Each point-spread function is a column of the MRM for that inversion; the value of each element in the column is assigned to the corresponding model cell. The point-spread functions for other model cells were similar to the ones shown here.
Figure 2. The layers of differing velocity in the tomograms correspond roughly to Units $1-4$. Both tomograms also contain a lowvelocity $(\sim 2100 \mathrm{~m} / \mathrm{s})$ wedge above $4-\mathrm{m}$ depth near $\mathrm{C} 4$, which corresponds to Unit 5. The correspondence between P-wave velocity and porosity at the BHRS is not exact (Moret et al., 2004), but porosity and velocity generally have an inverse relationship, a pattern borne out by the results shown here.

The largest discrepancy between the tomograms and the stratigraphic analysis of Barrash and Clemo (2002) is in the positions of the unit boundaries, which in some places differ by up to $2 \mathrm{~m}$. The $1-\mathrm{m}$ grid size used in the inversion makes submeter resolution impossible. Also, the large wavelength of the seismic data $(\sim 2 \mathrm{~m})$ may preclude greater resolution (e.g., Williamson and Worthington, 1993; Schuster, 1996). The largest discrepancy between the tomograms and the porosity-defined units is at the bottom of Unit 3. In well C4, Barrash and Clemo (2002) identified the depth to the

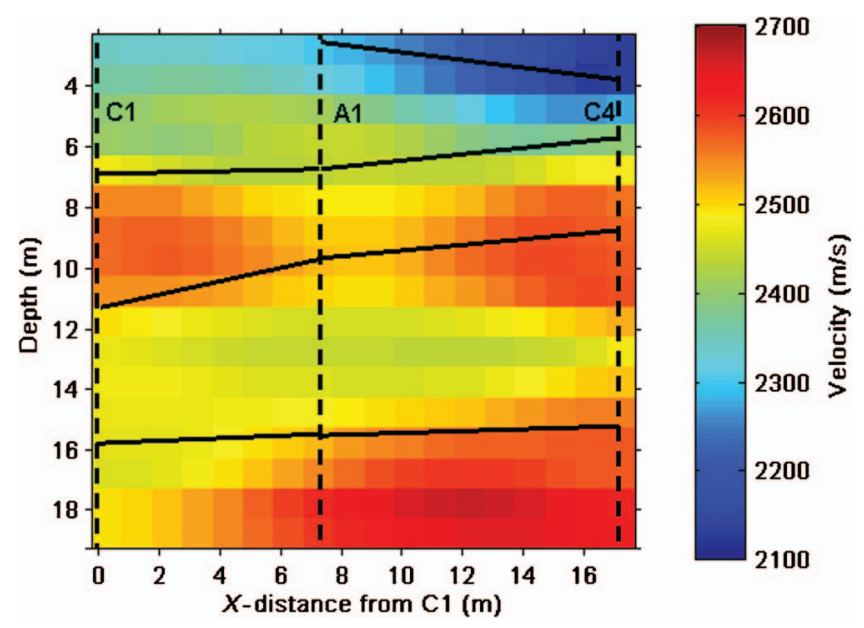

Figure 13. A comparison of the tomogram produced using crosswell data with the stratigraphic unit boundaries interpreted by Barrash and Clemo (2002). The units are identical to the ones in Figure 2 ; the tomogram is identical to Figure 8a.

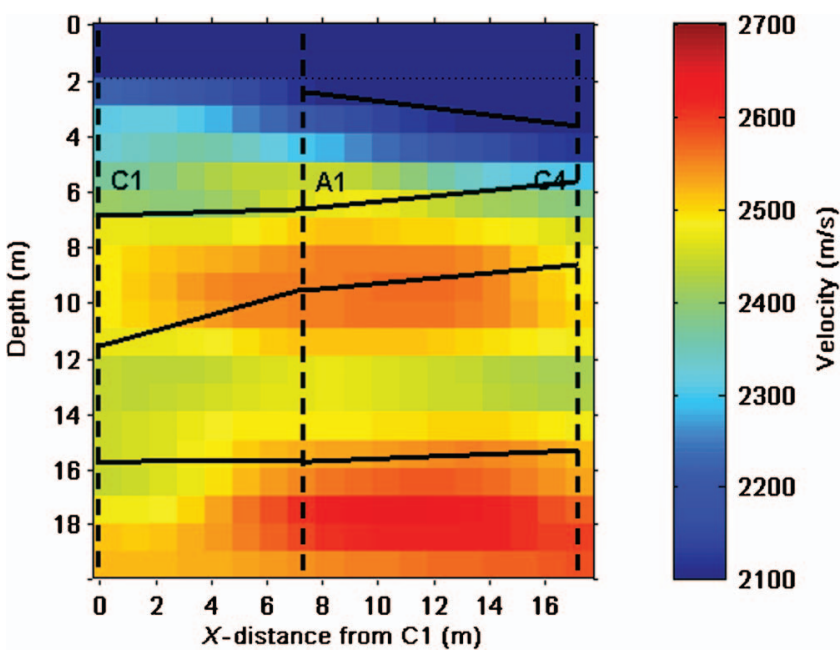

Figure 14. A comparison of the tomogram produced using crosswell and borehole-to-surface data with the stratigraphic unit boundaries interpreted by Barrash and Clemo (2002). The units are identical to the ones in Figure 2; the tomogram is identical to Figure 9a. 
bottom of Unit 3 as $8.69 \mathrm{~m}$, but in the tomogram the boundary appears to be about 11-m depth, and the highest-velocity area of the layer is below the boundary interpreted from porosity logs. This discrepancy may be a result of the limited resolution of the tomogram, uncertainty in the location of the boundary interpreted from the neutron porosity logs, or the nonunique relationship between P-wave velocity and porosity at the BHRS (Moret et al., 2004).

\section{Value of borehole-to-surface information}

A comparison of Figures 13 and 14 suggests that the inclusion of borehole-to-surface data can improve crosswell seismic tomograms. The presence of $\mathrm{X}$-shaped artifacts in tomograms is attributable to a lack of crossing rays (e.g., Zhou, 2003), that is, to poor angular coverage. The tomogram produced using both the crosswell and the borehole-to-surface data (Figure 14) has better angular coverage, and thus does not contain an X-shaped artifact. A possible negative consequence of including the borehole-to-surface data is that the velocities in Figure 14 are slightly lower near the wells than the velocities at the same depth in the center of the tomogram. This feature may be an inversion artifact or it may reflect the presence of a disturbed zone near the wells.

The inclusion of the borehole-to-surface data also improves the ability of the inversion to image structure near the top of the panel. The slow zone corresponding to Unit 5 agrees much more accurately with the boundaries interpreted from porosity logs in Figure 14 than in Figure 13. The improved angular coverage provided by the borehole-to-surface data allows Unit 5 to be imaged more accurately.

Figures 10-12 show that the inclusion of the borehole to surface data does not appear to improve the resolution or uncertainty of the velocity model. This may be an indication that the effect of the borehole-to-surface data on the resolution and uncertainty is considerably less than that of the regularization.

\section{CONCLUSIONS}

We found seismic tomography to be an effective method for characterizing the P-wave velocity stratigraphy of the BHRS. We attribute the success of the experiment to careful attention to well deviation, data QC, and the choice of inversion parameters. The two-grid inversion routine gave us both accurate forward modeling and smooth ray density distributions. We evaluated our results using ray density plots, different reference models, model covariance matrices, and model resolution matrices. These techniques allowed us to assess the reliability of the velocity models, an important step to take before interpretation.

Including borehole-to-surface data in the inversion produced tomograms that did not exhibit the X-shaped pattern that is a common artifact in crosswell tomography; however, these tomograms do have slightly lower velocities near the wells than in the center. This latter type of artifact could be eliminated by using a zonal tomography routine that severely limits the variability of the velocity field. The inclusion of the borehole-to-surface data also improved the routine's ability to image structure near the top of the panel. The resolution and uncertainty of the inversions were not improved by the inclusion of the borehole-to-surface data. This lack of improvement may reflect a strong dependence of MRM and MCM on the regularization used.

The seismic velocity models contain distinct regions that correspond well to the stratigraphic units previously identified from the neutron porosity logs, even though the lithologic differences are subtle. The higher-porosity units correspond to lower-velocity regions and vice versa. Thus, our results provide independent confirmation of the neutron log stratigraphy. The boundaries between the regions of differing velocities and the neutron log stratigraphy boundaries disagree by as much as $2 \mathrm{~m}$. Our accuracy in locating the boundaries between units was limited by the grid size of the inversion and the wavelength of the data.

This study has shown that crosswell seismic tomography with borehole-to-surface data included can be an effective tool for imaging the velocity structure of the shallow subsurface. The resolution of the velocity models is limited by the frequency of the data, the grid size, and the angular coverage. Future experiments could overcome these limitations by acquiring data with a higher-frequency source, using a multiscale tomography routine, and including the traveltimes of reflections from known interfaces. The level of resolution achieved in this study, however, is high enough to distinguish the major sedimentary units at the site.

\section{ACKNOWLEDGMENTS}

We would like to thank M. L. Buursink for providing the borehole deviation logs and S. E. Goldstein for sharing the results of her refraction experiment. S. Shedlock of Sub-Terra Surveys provided the sparker source we used for this experiment. D. F. Aldridge provided the tomography routine that we used as framework for the routine discussed here. F. Day-Lewis, C. Ammon, the associate editor, and several anonymous reviewers provided helpful comments. The Army Research Office (DAAD19-00-1-0454 and DAAH-96-1-0318) and the Environmental Protection Agency (X97008501-0) funded this work.

\section{REFERENCES}

Aldridge, D. F., and D. W. Oldenburg, 1993, Two-dimensional tomographic inversion with finite-difference traveltimes: Journal of Seismic Exploration, 2, 257-274.

Alumbaugh, D. L., 2000, Linearized and non-linear parameter variance estimation for two-dimensional electromagnetic induction inversion: Inverse Problems, 16, 1323-1341.

Alumbaugh, D. L., and G. A. Newman, 2000, Image appraisal for 2-D and 3-D electromagnetic inversion: Geophysics, 65, 1455-1467.

Ammon, C. J., and J. E. Vidale, 1993, Tomography without rays: Bulletin of the Seismological Society of America, 83, 509-528.

Barrash, W., and T. Clemo, 2002, Hierarchical geostatistics and multifacies systems: Boise Hydrogeophysical Research Site, Boise, Idaho: Water Resources Research, 38, 1196, doi: 10.1029/2002WR001436.

Barrash, W., T. Clemo, and M. D. Knoll, 1999, Boise Hydrogeophysical Research Site: Objectives, design, initial geostatistical results: Proceedings, SAGEEP, Environmental and Engineering Geophysics Society, 389-398.

Barrash, W., M. D. Knoll, D. W. Hyndman, T. Clemo, E. C. Reboulet, and E. M. Hausrath, 2003, Tracer/Time-Lapse Radar Imaging Test at the Boise Hydrogeophysical Research Site: Proceedings, SAGEEP, Environmental and Engineering Geophysics Society, 163-174.

Barrash, W., R. H. Morin, and D. M. Gallegos, 1997, Lithologic, hydrologic, and petrophysical characterization of an unconsolidated cobbleand-sand aquifer Capital Station site, Boise, Idaho: Proceedings of the 32nd Symposium On Engineering Geology and Geotechnical Engineering, 307-323.

Barrash, W., and E. C. Reboulet., 2004, Significance of porosity for stratigraphy and textural composition in subsurface coarse fluvial deposits, Boise Hydrogeophysical Research Site: Geological Society of America Bulletin, 116, 1059-1073, doi: 10.1130/B25370.1.

Bernabini, M., and E. Cardarelli, 1997, Variable damping factors in travel time tomography: Journal of Applied Geophysics, 38, 131-141.

Clement, W. P., M. D. Knoll, L. M. Liberty, P. R. Donaldson, P. Michaels, W. Barrash, and J. R. Pelton, 1999, Geophysical surveys across the Boise Hydrogeophysical Research Site to determine geophysical parameters of 
a shallow, alluvial aquifer: Proceedings, SAGEEP, Environmental and Engineering Geophysics Society, 399-408.

Curtis, A., 1998, Optimal cross-borehole tomographic geometries: Presented at the 68th Annual International Meeting, SEG Annual Meeting Expanded Abstracts, 797-800.

Daley, T. M., E. L. Majer, and J. E. Peterson, 2004, Crosswell seismic imaging in a contaminated basalt aquifer: Geophysics, 69, 16-24.

Dingman, S. L., 1994, Physical Hydrology: Macmillan Publishing Co.

Ellefsen, K. J., P. A. Hsieh, and A. M. Shapiro, 2002, Crosswell seismic investigation of hydraulically conductive, fractured bedrock near Mirro Lake, New Hampshire: Journal of Applied Geophysics, 50, 299-317.

Gheslagni, F., and J. C. Santamarina, 1998, Data pre-processing in crosshole geotomography: Journal of Environmental and Engineering Geophysics, 3, 41-47.

Hansen, P. C., 1992, Analysis of discrete ill-posed problems by means of the L-curve: SIAM Rev., 34, 561-580.

Hubbard, S. H., J. Chen, J. Peterson, E. L. Majer, K. H. Williams, D. J. Swift, B. Mailloux, and Y. Rubin, 2001, Hydrogeological characterization of the South Oyster bacterial transport site using geophysical data: Water Resources Research, 37, 2431-2456.

Hyndman, D. W., J. M. Harris, and S. M. Gorelick, 2000, Inferring the relation between seismic slowness and hydraulic conductivity in heterogeneous aquifers: Water Resources Research, 36, 2121-2132.

Jussel, P., F. Stauffer, and T. Dracos, 1994a, Transport modeling in heterogeneous aquifers, 1. Statistical description and numerical generation of gravel deposits: Water Resources Research, 30, 1803-1817.

Jussel, P., F. Stauffer, and T. Dracos, 1994b, Transport modeling in heterogeneous aquifers: 2 . Three-dimensional transport model and stochastic numerical tracer experiments: Water Resources Research, 30, 18191831.

Lanz, E., H. Maurer, and A. G. Green, 1998, Refraction tomography over a buried waste disposal site: Geophysics, 63, 1414-1433.

Liberty, L. M., W. P. Clement, and M. D. Knoll, 1999, Surface and borehole seismic characterization of the Boise Hydrogeophysical Research Site: Proceedings, SAGEEP, Environmental and Engineering Geophysics Society, 723-732.

Maurer, H. R., 1996, Systematic errors in seismic crosshole data: application of the coupled inverse technique: Geophysical Research Letters, 23 2681-2684.

Menke, W., 1984, Geophysical data analysis: Discrete inverse theory: Academic Press

Michelena, R. J., 1993, Singular value decomposition for cross-well tomography: Geophysics, 58, 1655-1661.

Miller, R. D., and J. Xia, 1998, Large near-surface velocity gradients on shallow seismic reflection data: Geophysics, 63, 1348-1356.

Moret, G. J. M., W. P. Clement, M. D. Knoll, and W. Barrash, 2004, VSP traveltime inversion: Near surface issues: Geophysics, 69, 345-351.

Musil, M., H. Maurer, A. Green, H. Horstmeyer, F. Nitsche, D. Vonder Muhll, and S. Springman, 2002, Shallow seismic surveying of an Alpine rock glacier: Geophysics, 67, 1701-1710.

Peretti, W. R., M. D. Knoll, W. P. Clement, and W. Barrash, 1999, 3-D GPR imaging of complex fluvial stratigraphy at the Boise Hydrogeophysical Research Site: Proceedings, SAGEEP, Environmental and Engineering Geophysics Society, 555-564.

Peterson, J. E., 2001, Pre-inversion corrections and analysis of radar tomographic data: Journal of Environmental and Engineering Geophysics, 6, $1-18$.

Rector, J. W., and J. K. Washbourne, 1994, Characterization of the resolution and uniqueness in crosswell direct-arrival traveltime tomography using the Fourier projection slice theorem: Geophysics, 59, 1642-1649.

Regli, C., P. Huggenberger, and M. Rauber, 2002, Interpretation of drill core and georadar data of coarse gravel deposits: Journal of Hydrology, 255, 234-252.

Schuster, G. T., 1996, Resolution limits for crosswell migration and traveltime tomography: Geophysical Journal International, 127, 427-440.

Squires, L. J., S. N. Blakeslee, and P. L. Stoffa, 1992, The effects of statics on tomographic velocity reconstructions: Geophysics, 57, 353-362.

Squires, L. J., P. L. Stoffa, and G. Cambois, 1994, Borehole transmission tomography for velocity plus statics: Geophysics, 59, 1028-1036.

Tarantola, A., and B. Valette, 1982, Generalized nonlinear inverse problems solved using the least squares criterion: Reviews of Geophysics and Space Physics, 20, 219-232.

Tronicke, J., P. Dietrich, and E. Appel, 2002, Quality improvement of crosshole georadar tomography: pre- and post-inversion data analysis strategies: European Journal of Environmental and Engineering Geophysics, 7, 59-73.

Vasco, D. W., J. E. Peterson, and E. L. Majer, 1996, Non-uniqueness in traveltime tomography: Ensemble inference and cluster analysis: Geophysics, 61, 1209-1227.

Williamson, W. R., and M. H. Worthington, 1993, Resolution limits in ray tomography due to wave behavior: numerical experiments: Geophysics, $\mathbf{5 8}, 727-735$.

Yoshizawa, K., and B. L. N. Kennett, 2002, Determination of the influence zone for surface wave paths: Geophysics Journal International, 149, $440-453$.

Zhou, H., 2003, Multiscale traveltime tomography: Geophysics, 68, 16391649 . 